\title{
BRONCHIECTASIS
}

\section{Comparison of exhaled and nasal nitric oxide and exhaled carbon monoxide levels in bronchiectatic patients with and without primary ciliary dyskinesia}

\author{
I Horváth, S Loukides, T Wodehouse, E Csiszér, P J Cole, S A Kharitonov, P J Barnes
}

Thorax 2003;58:68-72

Background: Primary ciliary dyskinesia (PCD) is associated with chronic airway inflammation resulting in bronchiectasis.

Methods: The levels of exhaled nitric oxide (eNO), carbon monoxide (eCO) and nasal NO ( $\mathrm{nNO}$ ) from bronchiectatic patients with PCD $(n=14)$ were compared with those from patients with non-PCD bronchiectasis without $(n=31)$ and with cystic fibrosis (CF) $(n=20)$ and from normal subjects $(n=37)$ to

See end of article for authors' affiliations assess the clinical usefulness of these measurements in discriminating between PCD and other causes of bronchiectasis.

Results: Exhaled NO levels were lower in patients with PCD than in patients with non-PCD non-CF bronchiectasis or healthy subjects (median (range) 2.1 (1.3-3.5) ppb $v 8.7$ (4.5-26.0) ppb, $\mathrm{p}<0.001$;

Correspondence to: Professor PJ Barnes, Department of Thoracic Medicine, National Heart and Lung Institute, Dovehouse Street, London SW3 6LY, UK;

p.j.barnes@ic.ac.uk

Revised version received 9 September 2002

Accepted for publication

11 September 2002 $6.7(2.6-11.9) \mathrm{ppb}, \mathrm{p}<0.001$, respectively) but not lower than bronchiectatic patients with CF (3.0 (1.5-7.5) ppb, p>0.05). Nasal levels of $\mathrm{nNO}$ were significantly lower in PCD patients than in any other subjects (PCD: 54.5 (5.0-269) ppb, non-PCD bronchiectasis without CF: 680 (310-1000) ppb, non-PCD bronchiectasis with CF: 343 (30-997) ppb, control: 663 (322-1343) ppb). In contrast, eCO levels were higher in all patient groups than in control subjects (PCD: 4.5 (3.0-24.0) ppm, p<0.01, other bronchiectasis without CF: 5.0 (3.0-15.0) ppm, p<0.001; CF: 5.3 (2.0-23.0) ppm, p<0.001 v $3.0(0.5-5.0) \mathrm{ppm})$. Low values in both eNO and $\mathrm{nNO}$ readings $(<2.4 \mathrm{ppb}$ and $<187 \mathrm{ppb}$, respectively) identified PCD patients from other bronchiectatic patients with a specificity of $98 \%$ and a positive predictive value of $92 \%$.

Conclusion: The simultaneous measurement of eNO and $\mathrm{nNO}$ is a useful screening tool for PCD.

$\mathrm{P}$ rimary ciliary dyskinesia (PCD) is a genetic disease characterised by defective motility of cilia resulting in impaired mucociliary clearance and infertility in most cases. $^{1}$

Decreased ciliary motility with secondary microbial colonisation in the airways leads to chronic airway inflammation and bronchiectasis. Oxidants and inflammatory mediators released from activated inflammatory cells in airways may lead to the induction of inducible nitric oxide synthase (iNOS) producing nitric oxide (NO) and inducible heme oxygenase (HO-1) releasing carbon monoxide (CO). In pulmonary diseases associated with chronic airway inflammation, such as asthma, expression of iNOS and HO-l is increased in the airways and levels of $\mathrm{NO}$ and $\mathrm{CO}$ are raised in exhaled breath. ${ }^{3-5}$ Increased levels of exhaled $\mathrm{NO}(\mathrm{eNO})$ and $\mathrm{CO}(\mathrm{eCO})$ correlate with other markers of airway inflammation in asthma. ${ }^{5-7}$ Concentrations of eNO and eCO are also increased in patients with bronchiectasis, which may reflect iNOS and HO-1 expression in macrophages and neutrophils in the airways of these patients. $^{89}$

Patients with PCD may represent a unique group of subjects, however, as eNO and nasal NO (nNO) levels are abnormally low in patients with PCD with documented bronchiectasis. ${ }^{10}{ }^{11}$ Nasal NO is also lower in children with Kartagener's syndrome (a condition in which PCD is associated with situs inversus) compared with healthy control children, ${ }^{2}{ }^{12}$ suggesting a defect in the function and/or expression of NO synthases. The level of eNO and nNO in patients with PCD may not reflect the chronic inflammatory process in the airways and might not be used as a non-invasive inflammatory marker, but it may be useful in diagnosing PCD as a cause of bronchiectasis in these patients. Expression and/or function of HO-1, however, may not be defective in patients with PCD and the level of eCO may reflect the chronic inflammatory process in these subjects.

We have therefore measured eNO, eCO, and nNO levels simultaneously in bronchiectatic patients with PCD and compared these values with those obtained from age matched healthy subjects, and patients with non-PCD bronchiectasis, with and without cystic fibrosis (CF). We included bronchiectatic patients with CF because CF may present with symptoms of chronic inflammation of the upper and/or lower airways, similar to PCD. Furthermore, eNO and nNO levels are lower than normal not only in PCD, but also in CF. ${ }^{13}$

\section{METHODS \\ Subject characteristics}

Four groups of subjects participated in the study (tables 1 and 2 ). Patients with bronchiectasis (PCD and non-PCD without CF) were recruited from the Host Defence Unit at the Royal Brompton Hospital and control subjects were recruited from staff members and examined at the Asthma Laboratory at the Royal Brompton Hospital, London. Bronchiectatic patients with CF were recruited from those attending an outpatient clinic for a scheduled visit at the National Koranyi Institute for Pulmonology, Budapest and examined at the Department of Pathophysiology at the same institute. Patients had no evidence of exacerbations for at least 4 weeks before the study. PCD was proved clinically and confirmed functionally ( saccharin test $>60$ min and abnormal ciliary beat frequency/ dyskinetic beat pattern) and morphologically at the PCD clinic of the Royal Brompton Hospital. Patients with PCD had ciliary defects (dynein arm abnormalities, $\mathrm{n}=6$; microtubular transposition, $\mathrm{n}=1$, documented by electron microscopy of ciliary nasal epithelium obtained either by nasal brushing or biopsy) 
Table 1 Mean (SD) subject characteristics

\begin{tabular}{|c|c|c|c|c|}
\hline & \multirow[b]{3}{*}{ Control $(n=37)$} & \multicolumn{3}{|l|}{ Bronchiectasis } \\
\hline & & \multirow[t]{2}{*}{$\operatorname{PCD}(n=14)$} & \multicolumn{2}{|l|}{ Non-PCD } \\
\hline & & & $\begin{array}{l}\text { Without CF } \\
(n=31)\end{array}$ & $\begin{array}{l}\text { With CF } \\
(n=20)\end{array}$ \\
\hline Age (years) & $33(2.8)$ & $35(4.6)^{*}$ & $45(5.1)^{*}$ & $25.7(2.4)$ \\
\hline $\operatorname{Sex}(M / F)$ & $20 / 17$ & $8 / 6$ & $16 / 15$ & $12 / 8$ \\
\hline $\mathrm{FEV}_{1}(\%$ predicted) & $94(0.8)$ & $51(5.1) \dagger$ & $58(6.1) \dagger$ & $53(5.9) \dagger$ \\
\hline FVC ( $\%$ predicted) & $99(0.4)$ & $72(4.2) \dagger$ & $77(3.1) \dagger$ & 74 (3.3)† \\
\hline $\mathrm{FEV}_{1} / \mathrm{FVC}$ & $0.81(0.001)$ & $0.62(0.04) \dagger$ & $0.65(0.02) \dagger$ & $0.62(0.04) \dagger$ \\
\hline Treatment & None & 7 IS & 19 IS; 2 OS & 8 IS \\
\hline
\end{tabular}

Table 2 Clinical characteristics of patients with bronchiectasis

\begin{tabular}{lrrr}
\hline & & Non-PCD & \\
\cline { 3 - 4 } & PCD & Without CF & With CF \\
\hline Neonatal respiratory symptoms & $6(43)$ & $2(6)$ & $7(35)$ \\
Chronic sputum production & $12(86)$ & $23(74)$ & $14(70)$ \\
Rhinosinusitis & $13(93)$ & $3(10)$ & $11(56)$ \\
Otitis media & $11(79)$ & $2(6)$ & $4(20)$ \\
Situs inversus & $6(43)$ & $0(0)$ & $1(5)$ \\
Infertility/subfertility & $11(79)$ & $0(0)$ & \\
\hline Data are given as number (\%) of patients. & &
\end{tabular}

or primary ciliary disorientation $(\mathrm{n}=7$, verified using a computerised improvision image analysis system)..$^{14}$ Bronchiectasis was diagnosed clinically and confirmed by high resolution computed tomographic (CT) scanning of the thorax in all patients. CF was confirmed by genetic analysis and a positive sweat test (chloride values $>60 \mathrm{mM}$ ). Patients with atopy, asthma, or reversible ( $>12 \%$ ) airway obstruction were excluded from the study. Normal control subjects had no history of chronic disease, were not receiving any regular medication, and had been free of respiratory infections for at least 6 weeks before the study. None of the subjects reported being current cigarette smokers or being exposed to smoke for more than 0.5 hours/day; this was confirmed by testing their urinary cotinine level with NicCheck I (DynaGen Inc, Cambridge, MA, USA). ${ }^{15}$

The study protocol was approved by the research ethics committees of both institutions and informed consent was obtained from all subjects.

\section{Study design}

Exhaled NO, eCO, and nNO were measured and spirometric tests were then performed. Forced expiratory volume in 1 second $\left(\mathrm{FEV}_{1}\right)$ and forced vital capacity $(\mathrm{FVC})$ were measured using a dry spirometer (Vitalograph, Buckingham, UK) and the best of three manoeuvres was expressed as a percentage of the predicted normal value.

\section{Measurement of eNO, eCO and nNO}

Exhaled $\mathrm{NO}$ and $\mathrm{CO}$ were measured simultaneously and $\mathrm{nNO}$ was then determined. Exhaled NO was measured using a chemiluminescence analyser (Model LR2000, Logan Research, UK) sensitive to NO from 1 to $5000 \mathrm{ppb}$ by volume with a resolution of $0.3 \mathrm{ppb}$. Exhaled $\mathrm{CO}$ was determined with an electrochemical sensor connected to the NO analyser. The analyser was designed for online recording of exhaled NO and $\mathrm{CO}$ concentrations. Measurement of eNO and eCO were made by slow exhalation $(5-6 \mathrm{l} / \mathrm{min})$ from total lung capacity for 20-30 s against a resistance $(3(0.4) \mathrm{mm} \mathrm{Hg})$ to prevent nasal contamination. An end expiratory plateau of at least $3 \mathrm{~s}$ was the end point of the measurement and values of eNO and eCO were read at this plateau. Participants repeated the manoeuvre until two acceptable tests were performed (difference between readings $<5 \%$ ).

Levels of nNO were measured using a Teflon tube which was inserted just inside one nostril while the contralateral nostril was left open. Air was sampled at $250 \mathrm{ml} / \mathrm{min}$ continuously from one nostril via the other nostril during a breath hold maintained as long as possible. NO concentration was recorded when the value reached the plateau. Nasal $\mathrm{CO}_{2}$ was also monitored to ensure exhalation was not taking place. This test was repeated twice and the mean value calculated.

The same model of analyser was used in both laboratories and measurements were performed by the same investigator to avoid any possible error arising from measurements taken at different sites. Both analysers were calibrated daily with certified NO mixtures (100 ppb) in nitrogen (BOC Special Gases, Guildford, UK). Two successive recordings were made and mean values were used in all calculations.

\section{Statistical analysis}

Age, $\mathrm{FEV}_{1}$, and FVC values are given as mean (SE). Mediator values are expressed as median (range). Differences between groups were analysed non-parametrically using the KruskalWallis test ( $p$ values of $<0.0001$ were considered significant). Pairwise comparisons using the Dunn's multiple comparison test were then carried out.

Spearman's rank correlation was used to determine the relationship between variables. Mean - 2SD values were calculated for nNO to obtain a cut off value for determining the specificity and sensitivity of the measurements. A p value of $<0.05$ was considered significant.

\section{RESULTS}

\section{Exhaled NO}

The concentration of eNO in patients with PCD and CF was significantly lower than that in healthy subjects (median (range) 2.1 (1.3-3.5) ppb; $\mathrm{p}<0.001$ and 3.0 (1.5-7.5) ppb; 

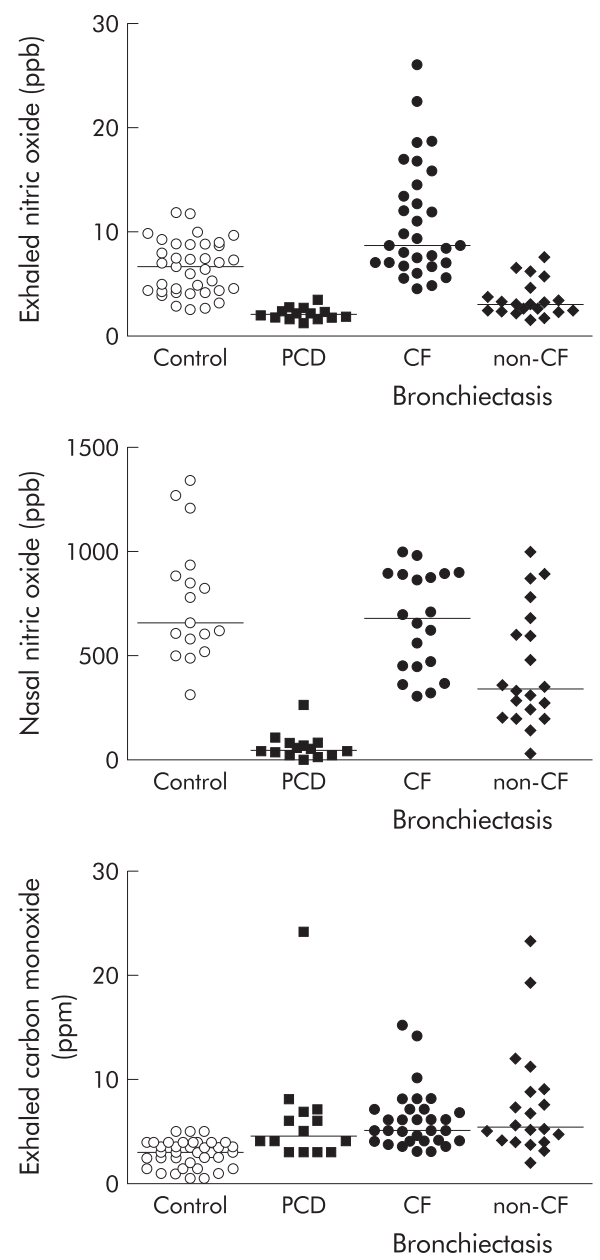

Figure 1 Exhaled nitric oxide, nasal nitric oxide, and exhaled carbon monoxide concentrations in normal subjects, patients with primary ciliary dyskinesia $(P C D)$ with documented bronchiectasis, and patients with non-PCD bronchiectasis with and without cystic fibrosis (CF). The Kruskal-Wallis test showed significant differences between mediator levels $(p<0.0001)$.

$\mathrm{p}<0.001$, respectively, $v 6.7(2.6-11.9) \mathrm{ppb})$. The level of eNO was significantly higher than normal in patients with non-PCD bronchiectasis without CF (8.7 (4.5-26.0) ppb; $\mathrm{p}<0.05)$. There was a significant difference in eNO values between non-CF bronchiectatic patients with and without PCD $(p<0.001)$. However, eNO values did not differ significantly between patients with PCD and those with CF ( $p>0.05$; fig 1). There was no significant difference in eNO levels in patients treated with and without inhaled and/or oral steroids in any of the studied groups. When only data in patients without steroid treatment were compared between the different groups, similar differences were found as described for the pooled data (data not shown).

\section{Nasal NO}

Nasal NO measurements were obtained in all patients with PCD and CF, in 20 non-PCD, non-CF bronchiectatic patients, and in 17 healthy subjects. The nNO level was markedly reduced in bronchiectatic patients with PCD (median (range) 54.5 (5-269) ppb) compared with normal controls (663 (322$1343)$ ppb; $<<0.001)$. Bronchiectatic patients with CF also had lower than normal levels of nNO (343 (30-997) ppb; $<<0.05$ ), but their nNO level was significantly higher than that of PCD patients $(\mathrm{p}<0.01)$. Nasal NO values of patients with non-PCD, non-CF bronchiectasis (680 (310-1000) ppb) were not significantly different from those in normal subjects. Patients with
PCD had significantly lower nNO levels than non-PCD, non-CF bronchiectatic patients $(p<0.001$, fig 1$)$. None of the patients was using nasal steroids and, when data were analysed without nNO values from patients on treatment with oral steroids $(n=2)$, similar differences were found between the groups.

\section{Exhaled CO}

Levels of eCO were significantly higher than normal in all patient groups (bronchiectasis with PCD: 4.5 (3-24) ppm, $\mathrm{p}<0.01$; non-PCD, non-CF bronchiectasis: 5 (3-15) ppm, $\mathrm{p}<0.001$; CF: 5.3 (2-23) ppm, $\mathrm{p}<0.001$; controls: 3 (0.55) $\mathrm{ppm}$ ). No differences in eCO values were seen between the different groups of patients (fig 1). There were a few outliers in eCO data (24 ppm in the PCD group, 19 and 23 ppm in the CF group) so the results were also analysed without these values, giving the following results: PCD patients: 4 (3-8) ppm, CF patients: $5(2-11) \mathrm{ppm}$; the values in both groups were significantly higher than those of the normal control group $(\mathrm{p}<0.01$ and $\mathrm{p}<0.001$, respectively $)$. No significant difference was detected between patients with and without steroid treatment.

\section{Sensitivity and specificity of the measurement of eNO and $\mathrm{nNO}$}

The sensitivity of eNO measurement in selecting PCD patients (number of PCD patients with low eNO reading/number of all patients with PCD in the population) was $79 \%$ when a cut off value of $2.4 \mathrm{ppb}$ was chosen. The specificity of eNO measurement (number of non-PCD bronchiectatic patients with negative test/number of all non-PCD bronchiectatic patients) at this cut off value was $85 \%$. The predictive value of a positive test (PPV; percentage of PCD patients with a positive result) was $69 \%$ and the predictive value of a negative test (NPV; percentage of patients with a negative test result from those patients who did not have PCD) was $94 \%$.

The sensitivity of nNO measurement was $93 \%$ and the specificity was $95 \%$ when the mean - 2SD of the nNO level in healthy subjects ( $187 \mathrm{ppb}$ ) was used as a cut off value (only two patients with CF had a value below the cut off level). The PPV of nNO measurement was $87 \%$ and its NPV was $97 \%$ in discriminating between PCD and non-PCD bronchiectatic patients.

If a positive result was described as low values in both eNO and nNO readings together in the same patient (eNO $<2.4 \mathrm{ppb}+\mathrm{nNO}<187 \mathrm{ppb}$ ), this identified PCD patients with a specificity of $98 \%$, PPV of $92 \%$, and NPV of $93 \%$.

\section{Correlations between variables}

There was no correlation between lung function and eNO, $\mathrm{nNO}$, or eCO values either when data were pooled or when data from steroid treated and non-treated subgroups were analysed separately or different subject groups were analysed separately (data not shown). Similarly, no relation was found between eNO and nNO readings or between eNO, nNO, eCO values and the age of subjects.

\section{DISCUSSION}

We have assessed the clinical usefulness of the simultaneous measurement of eNO and nNO in discriminating between PCD and other types of bronchiectasis. The reported specificity and sensitivity of the simultaneous measurements suggest that their combined use can be a valuable non-invasive screening tool for PCD. The measurement of nNO by itself has good diagnostic value. However, if a low nNO value is observed, determination of eNO and the combined evaluation of the two test results improves the diagnostic value by increasing its specificity and PPV. The measurement of eNO, however, cannot be used by itself for this purpose because of its low sensitivity and PPV. This study shows for the first time 
that patients with PCD have lower nNO values than those with any other types of bronchiectasis. It also shows that eNO values are lower in patients with PCD than in those with nonPCD, non-CF bronchiectasis, although there is no difference in eNO values between patients with PCD and CF bronchiectasis. In addition, we have shown that the eCO concentration is increased in patients with PCD to a similar extent to that in other types of bronchiectasis.

There was a significant difference in the mean age of the patients with CF and the other groups. This difference, however, probably did not influence our results because eNO and eCO values have been found not to be age related in adults. ${ }^{16}{ }^{17}$ Furthermore, there was no evidence of any relation between age and nNO values.

We found a modest increase in eNO levels in non-PCD, non-CF bronchiectatic patients compared with healthy subjects, with some overlap between the two groups. This increase was smaller than we had observed in patients with atopic asthma. ${ }^{18}$ This fits well with the notion that production of NO is linked to eosinophilic inflammation and that eNO levels are not as high in patients with airway inflammation dominated by neutrophils as in those with allergic asthma.

Some of our patients were treated with inhaled and/or oral steroids, but we could not detect any difference in eNO and eCO levels between patients with or without this treatment. Corticosteroids have been shown to reduce eNO levels profoundly in asthmatic patients ${ }^{19}$ and to decrease nNO levels in patients with allergic rhinitis. ${ }^{20}$ However, in patients with chronic suppurative upper and/or lower airway inflammation the results are somewhat contradictory. No difference was found in the eNO level between steroid treated and non-treated patients with $\mathrm{CF}^{13}$ while in patients with bronchiectasis one study showed a difference in the eNO level $^{8}$ but another did not. ${ }^{21}$ Differences between the results of these studies can be explained by differences in the techniques used for eNO measurement and by the fact that all of these studies (including the present one) were cross sectional. Prospective follow up studies are required to investigate the possible influence of steroid treatment on eNO values in bronchiectatic patients.

Because nasal symptoms (nasal polyps, sinusitis, persistent serous otitis media) are the main presenting features of PCD, it is important to consider the diagnosis of PCD in these cases. Could the measurement of nNO and eNO help to exclude PCD as an underlying cause of chronic upper airway symptoms? Nasal NO levels are extremely low in PCD. However, low nNO levels are also found in patients with chronic rhinosinusitis ${ }^{22}{ }^{23}$ which may therefore influence the diagnostic value of $\mathrm{nNO}$ measurement in discriminating between patients with PCD and those with rhinosinusitis from other causes. Although not specifically investigated in the present study, subjects with non-PCD, non-CF upper airway and sinus diseases had normal NO levels in the lower airways. ${ }^{22}$ The use of the combination of eNO and nNO measurements would therefore still have good specificity in identifying PCD.

In contrast to the results on NO levels, we found that eCO levels were raised in all patient groups studied compared with controls, with no difference between different conditions. In chronic airway infections increased HO-1 protein expression may result from the induction of the enzyme by inflammatory mediators such as interleukin- $1 \beta$, tumour necrosis factor- $\alpha$, interferon- $\gamma$ and hydrogen peroxide $\left(\mathrm{H}_{2} \mathrm{O}_{2}\right)$ present in the inflamed airways. ${ }^{23-26} \mathrm{HO}-1$ may be induced in various cells in the respiratory tract, including airway macrophages, ${ }^{4}$ epithelial cells, ${ }^{27}$ and infiltrating inflammatory cells such as neutrophils. In the present study there was no correlation between eCO levels and $\mathrm{FEV}_{1}$. This is not surprising as the decrease in $\mathrm{FEV}_{1}$ may be the result of structural changes due to repeated inflammation while increased eCO levels are more closely linked with the ongoing inflammatory process. Increased $\mathrm{CO}$ production may have multiple functions in the airways including antioxidant, pro-inflammatory, and antiinflammatory effects. ${ }^{25}$

The finding that eCO is increased equally in different inflammatory airway diseases including asthma, ${ }^{45}$ bronchiectasis, ${ }^{9}$ and $\mathrm{CF}^{28}$ suggests that $\mathrm{CO}$ production has a profound link with inflammatory processes regardless of their atopic or non-atopic nature.

In conclusion, this study has shown that combined measurement of eNO and nNO levels discriminates between bronchiectatic patients with PCD and those with bronchiectasis from other causes, which suggests that this measurement can be used as a non-invasive screening tool for PCD. On the other hand, increased levels of eCO found in all patient groups indicate that the activation of $\mathrm{CO}$ production is generally involved in these airway conditions.

\section{Authors' affiliations}

S Loukides, T Wodehouse, P J Cole, S A Kharitonov, P J Barnes, Department of Thoracic Medicine, National Heart and Lung Institute at Imperial College, London, UK

I Horváth, E Csiszér, Department of Pathophysiology, National Koranyi Institute for Pulmonology, Budapest, Hungary

This study was supported by the Hungarian National Scientific Research Foundation (OTKA-T030340) and by a joint grant of the British Council and the Hungarian OMFB (grant number: GB-31/98).

\section{REFERENCES}

1 Greenstone M, Rutman A, Dewar A, et al. Primary ciliary dyskinesia: cytological and clinical features. Q J Med 1988;253:405-30.

2 Pedersen $\mathbf{H}$, Mygind $\mathrm{N}$. Absence of axonemal arms in nasal mucosa cilia in Kartagener's syndrome. Nature 1976;262:494-5

3 Kharitonov SA, Yates D, Robbins RA, et al. Increased nitric oxide in exhaled air of asthmatic patients. Lancet 1994;343:146-7.

4 Horváth I, Donnelly LE, Kiss A, et al. Raised levels of exhaled carbon monoxide are associated with an increased expression of heme oxygenase- 1 in airway macrophages in asthma: a new marker oxidative stress. Thorax 1998.53:668-72.

5 Zayasu K, Sekizawa K, Okinaga S, et al. Increased carbon monoxide in exhaled air of asthmatic patients. Am J Respir Crit Care Med 1997; 156:1140-3

6 Kharitonov SA, Barnes PJ. Exhaled markers of pulmonary disease. Am J Respir Crit Care Med 2001;163:1693-722.

7 Horváth I, Kiss A, Barnes PJ. Relation of exhaled carbon monoxide to other markers of asthma in non-smoking patients. Am J Respir Crit Care Med 1998;157:A610.

8 Kharitonov SA, Wells AU, O'Connor BJ, et al. Elevated levels of exhaled nitric oxide in bronchiectasis. Am J Respir Crit Care Med 1995;151:1889-93.

9 Horváth I, Loukides S, Wodehouse T, et al. Increased levels of exhaled carbon monoxide in bronciectasis: a new marker of oxidative stress. Thorax 1998;53:867-70.

10 Loukides S, Kharitonov SA, Wodehouse T, et al. L-arginine increases nasal nitric oxide and improves mucociliary function in primary ciliary dyskinesia. Lancet 1998;352:371-2.

11 Karadag B, James AJ, Gultekin E, et al. Nasal and lower airway level of nitric oxide in children with primary ciliary dyskinesia. Eur Respir J 1999;13:1402-5.

12 Lundberg JON, Weitzberg E, Nordvall SL, et al. Primary nasal origin of exhaled nitric oxide and absence in Kartagener's syndrome. Eur Respir J 1994; 7: 1501-4

13 Thomas SR, Kharitonov SA, Scott SF, et al. Nasal and exhaled nitric oxide is reduced in adult patients with cystic fibrosis and does not correlate with cystic fibrosis genotype. Chest 2000;117:1085-9.

14 Rayner CF, Rutman A, Dewar A, et al. Ciliary disorientation in patients with chronic upper respiratory tract inflammation. Am J Respir Crit Care Med 1995;151:800-4.

15 Leischow SJ, Merikle EP, Cook G, et al. An evaluation of NicCheck I: a dipstick method for analyzing nicotine and its metabolites. Addict Behav $1999 ; 1: 145-8$

16 Ekroos H, Tuominen J, Sovijarvi AR. Exhaled nitric oxide and it long-term variation in healthy non-smoking subjects. Clin Physiol 2000;20:434-9.

17 Cunnington AJ, Normbrey P. Breath analysis to detect recent exposure to carbon monoxide. Postgrad Med 2002;78:233-8.

18 Horvath I, Donnelly LE, Kiss A, et al. Combined use of exhaled hydrogen peroxide and nitric oxide in monitoring asthma. Am J Respir Crit Care Med 1998;158:1042-6.

19 Keatings VM, Jatakanon A, Worsdell MY, et al. Effects of inhaled and oral glucocorticoids on inflammatory indices in asthma and COPD. Am J Respir Crit Care Med 1997;155:542-8.

20 Kharitonov SA, Rajakulasigam K, O'Connor B, et al. Nasal nitric oxide is increased in patients with asthma and allergic rhinitis and may be modulated by nasal glucocorticoids. J Allergy Clin Immunol 1997;99:58-64 
21 Ho JP, Innes JA, Greening AP. Exhaled nitric oxide is not elevated in the inflammatory airway diseases of cystic fibrosis and bronchiectasis. Eur Respir J 1998;12:1290-4

22 Arnal JF, Flores P, Rami J, et al. Nasal nitric oxide concentration in paranasal sinus inflammatory diseases. Eur Respir J 1999:13:307-12.

23 Lindberg S, Cervin A, Runer T. Nitric oxide (NO) production in the upper airways is decreased in chronic sinusitis. Acta Otolaryngol 1997; 117:113-7.

24 Eller J, Lapa-e-Silva JR, Poulter LW, et al. Cells and cytokines in chronic bronchial infection. Ann NY Acad Sci 1994;725:331-45.
25 Choi AMK, Alam J. Heme oxygenase-1: Function, regulation, and implication of a novel stress-inducible protein in oxidant-induced lung injury. Am J Respir Cell Mol Biol 1996;15:9-19.

26 Loukides S, Horváth I, Wodehouse T, et al. Elevated levels of expired breath hydrogen peroxide in bronchiectasis. Am J Respir Crit Care Med 1998;158:991-4.

27 Donnelly LE, Barnes PJ. Expression of heme oxygenase in human airway epithelial cells. Am J Respir Cell Mol Biol 2001;24:295-303.

28 Paredi P, Shah PL, Montuschi P, et al. Increased carbon monoxide in exhaled air of patients with cystic fibrosis. Thorax 1999;54:917-20.

\section{LUNG ALERT}

\section{Thrombolysis for submassive pulmonary embolism}

$\Delta$ Konstantinides S, Geibel A, Heusel G, et al. Heparin plus alteplase compared with heparin alone in patients with submassive pulmonary embolism. N Engl Med J 2002;347:1 143-50

his was a randomised placebo controlled trial of alteplase ( $100 \mathrm{mg}$ over 2 hours) with heparin $v$ placebo with heparin in 256 patients with submassive pulmonary embolism (PE) defined as echocardiographically detected PE; pulmonary artery hypertension with confirmation of PE by spiral computed tomography (CT); precapillary pulmonary hypertension with confirmation by CT; or new electrocardiographic signs of right ventricular strain followed by CT. Exclusion criteria included age $>80$ years, haemodynamic instability, and presentation more than 96 hours after onset of symptoms. In the alteplase group there was less escalation of treatment $(p=0.004)$ and a greater chance of 30 day event free survival $(\mathrm{p}=0.005)$. There was no difference in mortality or adverse events between the two groups.

This is the largest trial of thrombolysis in PE ever conducted, and it looks at the controversial group of patients with submassive PE showing significant benefit of alteplase. The absence of haemorrhagic complications was surprising.

T A R Seemungal

TSeemungal@aol.com 


\section{LETTERS TO THE EDITOR}

\section{Variations in mortality in acute COPD may reflect nihilism as well as resources}

I read with great interest the paper by Roberts et $a l^{1}$ and the accompanying editorial by Rudolf ${ }^{2}$. The study highlights important variations in the outcomes of patients with a common chronic disease, and once more illustrates that doctor:patient ratios may be an important contributor to this. It is also likely that some of the observed variation may arise as a result of variations in decision making by individual clinicians.

A recent study carried out in the eight hospitals in the Heart of England Critical Care network interviewed 98 clinicians who made end of life decisions for patients with chronic obstructive pulmonary disease (COPD). ${ }^{3}$ Each had made a median of 10 end of life decisions for COPD patients in the previous 12 months. There was considerable variability in the decision whether or not to admit identical patients to the critical care unit, with those choosing not to admit patients forming very pessimistic predictions of outcome compared with clinicians who would admit. It seems possible that poor outcomes for patients with COPD may not simply reflect a lack of resources, but also therapeutic nihilism that may have grown up over the years in response to the cognitive dissonance that arose when beds in critical care units could not be found for COPD patients in extremis. It seems likely that reversing variations in outcome will require both changes in resources and changes in clinicians' expectations. In this respect, the GMC guidance on withholding and withdrawing life prolonging treatments ${ }^{4}$ may well be helpful, particularly section 20 which recommends that "where there is a reasonable degree of uncertainty about the appropriateness of providing a particular treatment, treatment which may be of some benefit to the patient should be started until a clearer assessment can be made". In the Heart of England Critical Care network study over one third of clinicians would not admit a 75 year old COPD patient with single organ respiratory failure, yet in a recent study of over 3700 admissions of COPD patients of median age 67.8 years to UK intensive care units, those with single organ respiratory failure had a hospital survival of over $70 \%{ }^{5}$

It is important that chest physicians continue to be strident advocates for COPD patients admitted as emergencies, and take every opportunity to point out to their colleagues in general medicine and intensive care how well patients with COPD can do with both invasive and non-invasive ventilation.

M J Wildman

Health Services Research Unit, London School of Hygiene and Tropical Medicine, London WCIE 7HY UK; martin.wildman@lshtm.ac.uk

\section{References \\ 1 Roberts CM, Barnes S, Lowe D, et al. Evidence for a link between mortality in acute COPD and}

If you have a burning desire to respond to a paper published in Thorax, why not make use of our "rapid response" option?

Log on to our website (www.thoraxinl. com), find the paper that interests you, and send your response via email by clicking on the "eletters" option in the box at the top right hand corner.

Providing it isn't libellous or obscene, it will be posted within seven days. You can retrieve it by clicking on "read eletters" on our homepage.

The editors will decide as before whether to also publish it in a future paper issue.

hospital type and resources. Thorax 2003;58:947-9.

2 Rudolf $M$. Inpatient management of acute COPD: a cause for concern. Thorax 2003;58:914-5

3 Wildman MJ, O'Dea J, Kostopoulou O, et al. Variation in intubation decisions for patients with chronic obstructive pulmonary disease in one critical care network. Q J Med 2003;96:583-91.

4 General Medical Council. Withholding and withdrawing life-prolonging treatments: good practice. In: Decision-making. London: General Medical Council, 2002.

5 Wildman M, Harrison D, Brady AR, et al. Unit and hospital outcomes for 3752 admissions to 128 UK adult critical care units between 1995 and 2001. Thorax 2003;58(Suppl III):iii23.

\section{Authors' reply}

We thank Dr Wildman for his letter suggesting a further possible reason for the variation in outcome that we reported for the acute care of COPD patients in different hospital centres. In a further unpublished multiple regression analysis of the RCP/BTS 2001 audit we found that $26 \%$ of the variation in the outcome of death at 90 days following admission could be accounted for by factors measured in the study that included patient characteristics such as performance status and resource and organisational issues, as described in our paper. ${ }^{1}$ Dr Wildman suggests that individual clinicians might vary in determining admission to the ITU for COPD patients in respiratory failure, and suggests that respiratory physicians need to be advocates for their patients in this arena.

Attitudes and beliefs in what might be achieved are important but are difficult to measure in clinical practice. They might account for some of the variation in outcome but, if so, the therapeutic nihilism would have to vary systematically between whole hospitals to have been a factor in our study. Admission to the ITU depends on more than the individual attitude of the referring doctor. A lack of availability of beds may raise thresholds, and an institutional nihilism within the ITU may lead to rejection of suitable patients.

Perrin et $a l^{2}$ reported a study in which questionnaires regarding initiation of mechanical ventilation in end stage COPD patients were completed by 350 doctors subdivided by speciality (intensivists, respiratory specialists and other physicians). As in the paper by Wildman et al, ${ }^{3}$ there was considerable individual variation in decision making but no overall difference between the three types of specialist studied. However, no analysis by hospital or trust was made to identify local patterns. We believe all respiratory physicians will share Dr Wildman's call that referring physicians should be advocates for their patients, and this has to be matched by a willingness of the ITU staff to accept such patients and the availability of beds within an ITU/HDU facility to accommodate them. Perrin's paper provides hope of a generic match although individual disagreements may still occur. It is, however, not only admission to the ITU that matters, as in many hospitals non-invasive ventilatory support is provided on general wards by respiratory units without input from intensivists.

In the BTS/RCP 2003 national audit of the acute care of COPD patients, 95\% of all acute admitting sites have now registered to participate and data collection is nearing completion. Within the clinical data gathering there is a question that attempts to document clinical decision making when a patient eligible for ventilation on blood gas criteria does not receive ventilatory support. In addition, data regarding available resources such as ITU beds, bed occupancy, and numbers of ITU candidates transferred off site will be recorded. We may be in a position to shed further light on the issues of individual versus institutional nihilism or rationing in due course.

C M Roberts, M G Pearson Chest Clinic, Whipps Cross University Hospital, London E1 1 1NR, UK; mike@2doctors.freeserve.co.uk

\section{References}

1 Roberts CM, Barnes S, Lowe D, et al. Evidence for a link between mortality in acute COPD and hospital type and resources. Thorax 2003:58:947-9.

2 Perrin F, Renshaw M, Turton C. Clinical decision making and mechanical ventilation in patients with respiratory failure due to an exacerbation of COPD. Clin Med 2003;3:556-9.

3 Wildman MJ, O'Dea J, Kostopoulo O, et al. Variation in intubation decisions for patients with chronic obstructive pulmonary disease in one critical care network. Q J Med 2003;96:583-91.

\section{Do inhaled corticosteroids slow $\mathrm{FEV}_{1}$ decline in COPD after all?}

I question the findings of the meta-analysis by Sunderland et $a l^{1}$ and the content of the associated editorial by Burge and Lewis. ${ }^{2}$ The meta-analysis has drawn from available long term data from randomised controlled studies (RCTs) of inhaled corticosteroids (ICS) in chronic obstructive airways disease (COPD). The whole purpose of meta-analysis is to analyse such data systematically to answer a question. This study seems to use the data selectively to demonstrate an effect. Another recent meta-analysis-in my opinion properly conducted-drew on the same studies and reached the opposite conclusion. ${ }^{3}$ The fact is that four long term, adequately powered RCTs have examined the effect of ICS. All of these studies showed no effect of ICS on the primary outcome measure of decline in forced expiratory volume in 
l second $\left(\mathrm{FEV}_{1}\right)$. There may be a subset of people in whom the exacerbation rate is reduced, which was a secondary outcome in some of these studies.

In any case, as the authors point out, an annual difference of $7.7-9.9 \mathrm{ml}$ in $\mathrm{FEV}_{1}$ decline compared with placebo is of "debatable clinical importance" ${ }^{1}{ }^{1}$ It is hardly something to shout about, as occurred following this publication (probably egged on by the editorial) which was quoted in the GP press as suggesting that current widespread ICS use (albeit "off-label") was now clinically justified.

Another major problem with this study is that it does not analyse harm. For example, the largest RCT showed a significant reduction in bone mineral density of the lumbar spine and femur in patients receiving inhaled triamcinolone. ${ }^{4}$ People with COPD likely to receive ICS are frail and have poor mobility, so this finding raises particular concern as they are more likely to fall and falls could result in fracture. Even if inhaled triamcinolone is not used in the UK, fluticasone is Fluticasone has been the subject of particular cautionary advice because of its ability to cause systemic effects at high doses. ${ }^{6}$ If there is indeed a marginal clinical benefit from using these drugs, I think these people deserve a better assessment of risk and benefit than was presented in this metaanalysis and the accompanying editorial. ${ }^{2}$ The editorial claimed that it is no longer ethical to do more long term trials: surely the conclusion is the opposite? We need better data to justify the widespread use of ICS in COPD.

M G Duerden
Department of Medicines Management, Keele
University, Staffordshire ST5 5BG, UK;
martin@theduerdens.co.uk

\section{References}

1 Sutherland ER, Allmers H, Ayas NT, et al. Inhaled corticosteroids reduce the progression of airflow limitation in chronic obstructive pulmonary disease: a meta-analysis. Thorax 2003;58:937-41.

2 Burge PS, Lewis SA. So inhaled steroids slow the rate of decline of $\mathrm{FEV}_{1}$ in patients with COPD after all? Thorax 2003;58:911-3.

3 Highland KB, Strange C, Heffner JE. Long-term effects of inhaled corticosteroids on $\mathrm{FEV}_{1}$ in patients with chronic obstructive pulmonary disease. A meta-analysis. Ann Intern Med disease. A meta-analys

4 The Lung Health Study Research Group. Effect of inhaled triamcinolone on the decline in pulmonary function in chronic obstructive pulmonary disease. N Engl J Med 2000;343:1902-9.

5 News: NICE steroids advice for COPD thrown into doubt. Pulse 3 November 2003.

6 CSM/MCA. Reminder: Fluticasone propionate (Flixotide): use of high doses (>500 micrograms/ twice daily). Current Problems in

Pharmacovigilance August 2001.

\section{Ethics of placebo controlled studies of inhaled steroids for COPD}

The meta-analysis by Sutherland $e t$ al ${ }^{1}$ of the effect of inhaled corticosteroids on the progression of airflow limitation in patients with chronic obstructive pulmonary disease (COPD) found a small improvement in forced expiratory volume in 1 second $\left(\mathrm{FEV}_{1}\right)$ of $-7.7 \mathrm{ml} /$ year $(95 \% \mathrm{CI}-14.2$ to -1.3$)$ which is similar to the results of the meta-analysis performed by Highland et $a^{2} \quad(-5 \mathrm{ml} /$ year (95\% CI -11.2 to 1.2$)$ ) using a very similar data set. The meta-analyses employed slightly different study selection criteria and analytical techniques, and questioned the clinical significance of such small differences in $\mathrm{FEV}_{1}$. The selected primary studies suffered from potential drop-out bias and significant selection bias, in that almost all of the studies subjected to these meta-analyses excluded patients with a bronchodilator response. Studies of asthma and COPD as separate entities are limited because asthma and COPD (observed in cross section) represent a continuum, ${ }^{3}$ and the small number of available prospective observations indicates that asthma and COPD are sometimes different clinical manifestations of the same underlying aetiology evolving over time. ${ }^{4}$ Given all the uncertainties, questions and limitations, Highland et al ${ }^{2}$ concluded (correctly in my opinion) that "additional studies are needed to evaluate the effects on quality of life, risk for systemic side effects, doseresponse relationships in corticosteroidresponsive patients, and the economic effect of inhaled corticosteroids". On the other hand, in an editorial accompanying the paper by Sutherland et al, Burge and Lewis state: "It is no longer ethical to do more long term placebo controlled studies [of inhaled corticosteroids in COPD]". Given the uncertainties, questions and limitations which Burge and Lewis acknowledged, I was puzzled by this statement and would like to ask them why they reached this conclusion.

\section{L Hahn}

Dean Medical Center, East Clinic, 1821 S Stoughton Road, Madison, WI 53716, USA dlhahn@wisc.edu

\section{References}

1 Sutherland ER, Allmers H, Ayas NT, et al. Inhaled corticosteroids reduce the progression of airflow limitation in chronic obstructive pulmonary disease: a meta-analysis. Thorax 2003;58:937-41.

2 Highland KB, Strange C, Heffner JE. Long-term effects of inhaled corticosteroids on $\mathrm{FEV}_{1}$ in patients with chronic obstructive pulmonary disease. Ann Intern Med 2003;138:969-73.

3 Brand PL, Kerstiens HA, Postma DS, et al. Longterm multicentre trial in chronic nonspecific lung disease: methodology and baseline assessment in adult patients. Dutch CNSLD Study Group. Eur Respir J 1992;5:21-31.

4 Hahn DL. Chlamydia/mycoplasma: do they cause new-onset asthma in adults? In: Papadopoulos NG, ed. Respiratory infections in allergy and asthma. New York, Basel: Marcel Dekker, 2003;178:645-62.

5 Burge PS, Lewis SA. So inhaled steroids slow the rate of decline of $F E V_{1}$ in patients with COPD after all? Thorax 2003:58:911-3.

\section{Authors' reply}

To make randomised controlled studies ethical, the investigator must believe that neither treatment is known to be superior to the other. If the trial is to be placebo controlled, the investigator must believe that no nonallowed treatment is known to be of benefit. Both Drs Duerden and Hahn want more placebo controlled trials of inhaled corticosteroids (ICS) in COPD before they recommend their use. Our editorial pointed out that ICS were of established benefit in reducing exacerbations of COPD, ${ }^{1}$ so any future placebo controlled study would need to be in patients without a history of exacerbations. As exacerbations are associated with disease severity, and as about $80 \%$ of patients with an $\mathrm{FEV}_{1}<50 \%$ predicted have exacerbations over a 3 year period, ${ }^{2}$ any trial would need to be in those with early disease. The Copenhagen City Lung Study found that inhaled budesonide $800 \mu \mathrm{g} /$ day had no benefit in a population of smokers selected with a reduced $\mathrm{FEV}_{1} / \mathrm{FVC}$ ratio, the majority of whom had an $\mathrm{FEV}_{1}$ above $80 \%$ predicted. $^{3}$ This leaves the group with an $\mathrm{FEV}_{1}$ between $50 \%$ and $80 \%$ predicted, many of whom have not been identified by their medical practitioners. This was the group included in the EUROSCOP and Lung Health 2 studies, where the results included in the metaanalysis were the most divergent, probably because of the relatively low dose of ICS used in the Lung Health study. ${ }^{4}$ In the symptomatic patient with more severe disease, the combination of a long acting $\beta$ agonist and an ICS has been shown to be superior to either alone and is now the treatment of choice. ${ }^{67}$ This leaves the presymptomatic population in whom a decline in $\mathrm{FEV}_{1}$ is the only practical outcome measure. No randomised study using an intention to treat analysis has shown a reduction in $\mathrm{FEV}_{1}$ decline with any treatment in any disease, including ICS in asthma, although several studies have shown an improvement in $\mathrm{FEV}_{1}$ with ICS in COPD. ${ }^{246}$ Our editorial tried to explain why changes in $\mathrm{FEV}_{1}$ decline were difficult to show in patients with COPD. Patients with progressive disease are likely to be given ICS by their clinicians outside any trial, reducing the power of any study.

Any treatment should weigh the potential risks against any benefit. Dr Duerdin wants a better analysis of the risks of ICS in patients with COPD, particularly related to bone loss, and points out the reduced bone mineral density in the triamcinolone group in the Lung Health 2 study. ${ }^{5}$ The reported results are in 359/412 of a convenience sample who had three measurements of bone density. After 3 years the lumbar spine density reduced from 0.988 to $0.985 \mathrm{~g} / \mathrm{cm}^{2}$ and the femoral neck from 0.762 to $0.747 \mathrm{~g} / \mathrm{cm}^{2}$ in the triamcinolone group. EUROSCOP studied bone density measurements in 194 subjects $^{4}$ and showed very small changes which were significantly less at the femoral trochanter in the budesonide group (0.04\%/year $v 0.36 \%$ / year in the placebo group). Randomised controlled studies are probably not the best method for assessing the extent of long term adverse effects, but the evidence from the randomised studies to date shows that the risks are relatively minor compared with the risks of death from the natural progression of the disease. Introducing ICS at an earlier stage may alter the risk/benefit ratios. The adverse effects on the bones are probably best studied in asthmatics of whom many are already taking long term ICS in equivalent doses.

There is a striking difference between the way that cardiac and respiratory physicians greet new treatments whose individual effects are present but relatively minor. There has been a meaningful reduction in cardiac deaths attributed to the combination of several treatments with modest individual effects. This has resulted in more smokers living to develop significant COPD. It is likely that improvements in the quality and quantity of life in patients with COPD will come from a combination of treatments, among which ICS have a place. The main 
unanswered questions are-at which stage to start and what dose to use? Randomised trials in these areas are badly needed. They will require large numbers, enthusiasm from respiratory clinicians, and are likely to need public rather than pharmaceutical industry funding.

P S Burge

Birmingham Heartlands Hospital, Birmingham B9 5SS, UK; sherwood.burge@heartsol.wmids.nhs.uk

S A Lewis

Division of Respiratory Medicine, City Hospital, Nottingham, UK

\section{References}

1 Burge PS, Lewis SA. So inhaled steroids slow the rate of decline of $\mathrm{FEV}_{1}$ in patients with COPD after all? Thorax 2003;58:911-3.

2 Burge PS, Calverley PMA, Jones PW, et al. Randomised, double blind, placebo controlled study of fluticasone propionate in patients with moderate to severe chronic obstructive pulmonary disease: the ISOLDE trial. BMJ 2000;320: 1297-303.

3 Vestbo J, Sorensen T, Lange P, et al. Long-term effects of inhaled budesonide in mild and moderate chronic obstructive pulmonary disease a randomised controlled trial. Lancet 1999:353:1819-23.

4 Pauwels RA, Lofdahl C, Laitinen LA, et al, for the European Respiratory Society Study on Chronic Obstructive Pulmonary Disease. Long-term treatment with inhaled budesonide in persons with mild chronic obstructive pulmonary disease who continue smoking. N Engl J Med 1999;340:1948-53.

5 The Lung Health Study Research Group. Effect of inhaled triamcinolone on the decline in pulmonary function in chronic obstructive pulmonary disease. N Engl J Med 2000;343:1902-9.

6 Calverley PMA, Pauwels R, Vestbo J, et al, for the TRISTAN Study Group. Combined salmeterol and fluticasone in the treatment of chronic obstructive pulmonary disease: a randomised controlled trial. Lancet 2003;361:449-56.

7 Szafranski W, Cukier A, Ramirez A, et al. Efficacy and safety of budesonide/formoterol in the management of chronic obstructive pulmonary disease. Eur Respir J 2003;21:74-81.

\section{Delays in diagnosis of OSAHS}

We very much enjoyed the first paper in the review series on sleep and admired Stradling and Davies's honest appraisal of the current difficulties in defining disease and the lack of a relationship between symptoms and the results of investigations. ${ }^{1}$ One of the problems of truly determining the size of the health burden associated with the obstructive sleep apnoea/hypopnoea syndrome (OSAHS) is that much of the burden may occur before the diagnosis is made. Others have shown how use of hospital resources and use of cardiovascular medication is high in those with undiagnosed obstructive sleep apnoea. ${ }^{2}$ We administered a questionnaire to 166 consecutive patients with diagnosed OSAHS on continuous positive airway pressure treatment and asked them to identify how long they could recall having symptoms at the time of diagnosis. In 155 cases $(93.4 \%)$ someone had previously complained of the patient's loud snoring and first mention of this had been made a median of 12 years (range 2-52) before diagnosis of OSAHS. In $84.3 \%$ of respondents excessive daytime sleepiness had been present for a median of 8 years (range 0.5-62) and 133 patients $(80.1 \%)$ reported that their bed partner had witnessed apnoeas a median of 8 years (range 1-49) before diagnosis. We also found that, of the $119(71.7 \%)$ who were drivers, 26 $(21.8 \%)$ reported at least one or more automobile crashes in the previous 5 years, with seven respondents having had two and one having had four.

These results suggest a lack of awareness of sleep related breathing disorders among the general population and probably among health professionals. The delay in diagnosis is likely to have significant effects on morbidity, and in recent preliminary work it has been shown that those with OSASHS have structural changes in brain morphology compared with healthy controls. ${ }^{4}$ In addition to the health and quality of life benefits to the individual to be gained by prompt diagnosis, there are also economic aspects in favour of prompt diagnosis and treatment ${ }^{56}$ and early benefits in terms of driving performance.

R Ghiassi, K Murphy, M R Partridge

The Sleep Laboratory, Charing Cross Hospital, London W6 8RF, UK

Correspondence to: Professor M R Partridge, Department of Respiratory Medicine, Imperial College London, Charing Cross Campus, London W6 8RP, UK; m.partridge@imperial.ac.uk

\section{References}

1 Stradling JR, Davies RJO. Sleep · 1: Obstructive sleep apnoea/hypopnoea syndrome: definitions, epidemiology and natural history. Thorax 2004:59:73-8.

2 Kryger MH, Roos L, Delaive K, et al. Utilisation of health care services in patients with severe obstructive apnoea. Sleep 1996;19:S111-6.

3 Otake K, Delaive K, Walld R, et al. Cardiovascular medication use in patients with undiagnosed obstructive sleep apnoea. Thorax 2002;57:417-22.

4 Morrell M, McRobbie D, Quest R, et al. Changes in brain morphology associated with obstructive sleep apnoea. Sleep Med 2003;4:451-4.

5 Pelletier-Fleury N, Meslier N, Gagnadoux F, et al. Economic arguments for the immediate management of moderate to severe obstructive sleep apnoea syndrome. Eur Respir J 2004;23:53-60.

6 Douglas NJ, George CFP. Treating sleep apnoea is cost effective. Thorax 2002;57:93.

7 Turkington PM, Sircar M, Saralaya D, et al. Time course of changes in driving simulator performance with and without treatment in patients with sleep apnoea/hypopnoea syndrome. Thorax 2004;59:56-9.

\section{Prophylactic antibiotic treatment of bronchiectasis with azithromycin}

Once a treatable cause of bronchiectasis such as hypogammaglobulinaemia has been excluded, management largely involves physiotherapy and treatment of infective exacerbations with appropriate antibiotics. ${ }^{1}$ In a proportion of patients this is not adequate to prevent frequent infective exacerbations. Prophylactic antibiotic treatment can be used to try to prolong the exacerbation free period. This may be administered orally, via a nebuliser, or using a cyclical regimen of intravenous antibiotics. Prophylactic treatment may be problematic due to side effects and development of antibiotic resistance. ${ }^{2}$ Macrolide antibiotics exhibit immunomodulating properties. Long term, low dose erythromycin has been shown in diffuse panbronchiolitis, a disease with some similarities to idiopathic bronchiectasis, to be effective in controlling chronic suppurative airways disease. ${ }^{3}$ Recently published research has shown benefits of long term azithromycin treatment in patients with cystic fibrosis. ${ }^{4}$ These results led us to consider using azithromycin as prophylaxis in patients with non-cystic fibrosis bronchiectasis with frequent infective exacerbations.

Patients attending the outpatients department between February 1999 and April 2002 who fulfilled the following criteria were considered for azithromycin prophylaxis:

- bronchiectasis defined by CT scan;

- any causal condition had been treated if possible;

- general management optimised;

- $>4$ documented infective exacerbations requiring oral or intravenous antibiotic treatment during the last 12 months;

- Pseudomonas aeruginosa respiratory infection, if present, had not responded to nebulised antibiotic prophylaxis or this had not been tolerated;

- failure to control chronic symptoms.

Exclusions included allergy to macrolides and abnormal liver function tests. The dosing schedule was $500 \mathrm{mg}$ once daily for 6 days, $250 \mathrm{mg}$ once daily for 6 days, then $250 \mathrm{mg}$ on Monday/Wednesday/Friday of each week. A safety blood examination was organised 1 month after starting treatment. The patients were fully reviewed at least 4 months after commencement of azithromycin prophylaxis and lung function tests repeated. Sputum culture results before and after starting prophylaxis were noted. Statistical analysis was performed using a paired $t$ test and non-parametric Wilcoxon test.

Thirty nine patients were studied. Fifteen had idiopathic bronchiectasis and the remainder consisted of 13 with post childhood infections, five with primary ciliary dyskinesia, five with common variable immunodeficiency, and one with Young's syndrome. Their mean (SD) age was 51.9 (16.1) years (range 18-77) with a 2:1 female predominance. All patients had had more than four documented exacerbations during the previous 12 months. Six patients stopped taking the azithromycin prophylaxis because of side effects: abnormal liver function tests $(\mathrm{n}=2)$, diarrhoea $(\mathrm{n}=2)$, rash $(\mathrm{n}=1)$, and tinnitus $(n=1)$. All occurred during the first month of treatment. Other side effects experienced were mild and mainly gastrointestinal. Five patients were on long term oral corticosteroids with no change in dosage, in two new inhaled corticosteroids were introduced, and one patient was given a short 7 day reducing course of oral corticosteroids. The mean (SD) length of time taking azithromycin, excluding those who stopped because of side effects, was 20 (10.1) months (range 4-38). Twenty six patients are continuing with the prophylaxis at the present time; in the other seven treatment was discontinued because of improvement in their condition.

Sputum culture results (all bacteria isolated) before commencement showed no growth $(\mathrm{n}=13), \quad$ Pseudomonas aeruginosa $(\mathrm{n}=8)$, Staphylococcus aureus $(\mathrm{n}=6)$, Haemophilus influenzae $(\mathrm{n}=6)$, Streptococcus pneumoniae $(\mathrm{n}=3)$, Stenotrophomonas maltophilia $(\mathrm{n}=2)$, Morexella catarrhalis $(\mathrm{n}=1)$, not done $(\mathrm{n}=4)$. After 4 months the results were no growth $(\mathrm{n}=18), P$ aeruginosa $(\mathrm{n}=5)$, 
Table 1 Change in symptoms while taking azithromycin prophylaxis

\begin{tabular}{lllll}
\hline & Mean & SD & SE & p value \\
\hline Sputum volume & 1.6 & 0.8 & 0.14 & $<0.001$ \\
Sputum colour & 2.1 & 0.7 & 0.13 & $<0.001$ \\
Sputum consistency & 2.5 & 0.6 & 0.11 & 0.006 \\
Cough & 2.4 & 0.7 & 0.12 & 0.001 \\
Fatigue & 2.1 & 1.0 & 0.18 & 0.001 \\
Exercise tolerance & 3.8 & 0.9 & 0.16 & 0.002 \\
Wheeze & 2.6 & 0.8 & 0.14 & 0.011 \\
Breathlessness & 2.3 & 0.7 & 0.13 & 0.002 \\
\hline
\end{tabular}

Symptoms scored on a 5 -point scale: $1=$ large decrease, $2=$ decrease, $3=$ no change, $4=$ increase, $5=$ large increase in symptoms.

$S$ aureus $(\mathrm{n}=1), S$ pneumoniae $(\mathrm{n}=1)$. not done $(\mathrm{n}=10)$. In three patients who had cultured $P$ aeruginosa before starting azithromycin prophylaxis the organism was not recultured at follow up.

In the 33 patients completing at least 4 months treatment there was a statistically significant reduction in infective exacerbations requiring oral antibiotics from a mean of 0.71 per month to 0.13 per month $(\mathrm{p}<0.001)$. There was also a reduction in the requirement for intravenous antibiotics from a mean of 0.08 courses per month to 0.003 courses per month $(\mathrm{p}<0.001)$. Subgroup analysis of patients with $P$ aeruginosa isolated before starting azithromycin prophylaxis showed no difference compared with all patients included $(p=0.22)$. Twenty five patients had lung function tests before and after at least 4 months of treatment (range 4-20 months). There was an improvement in all lung function parameters but the improvement in carbon monoxide transfer factor (TLCO) was the only one to reach statistical signficance $(\mathrm{p}=0.01)$.

Symptom data were collected from 32 patients and scored on a 5-point scale (table 1). Statistical analysis using a nonparametric Wilcoxon test showed that there was a significant improvement in all symptoms.

The mechanism by which azithromycin reduces the number of infective exacerbations and chronic symptoms is unknown, but it is likely to be multifactorial. It may be due to downregulation of the host immune response by azithromycin, so decreasing host mediated tissue damage as postulated in the vicious circle hypothesis. It might also benefit patients by reducing bacterial load and therefore the stimulation for neutrophilic inflammation, or by influencing the pathogenic mechanisms of bacteria. Macrolide antibiotics have also been shown to reduce mucus secretion. ${ }^{15}$

Currie et al compared high dosage amoxicillin with placebo over an 8 month period and found a greater reduction in the volume of purulent sputum between exacerbations in the amoxicillin group (to $20 \%$ of pretreatment volume) than in the placebo group, but did not demonstrate any reduction in infective exacerbations. ${ }^{6}$ The superior findings of our study suggest that the anti-inflammatory effects of azithromycin were important in achieving the results obtained. This study was performed with patients who were sufficiently unwell to preclude consideration of a placebo group. The patients therefore acted as their own controls. The results are sufficiently impressive to encourage the design of a randomised study, either enrolling less sick patients and having a placebo comparator or using a comparator antibiotic without immunomodulating properties.

G Davies, R Wilson

Host Defence Unit, Royal Brompton Hospital,

London, UK

Correspondence to: Dr R Wilson, Host Defence Unit, Royal Brompton Hospital, Sidney Street, London SW3 6NP, UK; r.wilson@rbh.nthames.nhs.uk

\section{References}

1 Wilson R. Bronchiectasis. In: Gibson J, Geddes D, Costabel U, eds. Respiratory medicine, 3rd ed. Edinburgh: WB Saunders, 2002:1145-464.

2 Rayner CF, Tillotson G, Cole PJ, et al. Efficacy and safety of long-term ciprofloxacin in the management of severe bronchiectasis. J Antimicrob Chemother 1994;34:149-56.

3 Kudoh S. Erythromycin treatment in diffuse panbronchiolitis. Curr Opin Pulm Med 1998;4:116-21.

4 Wolter J, Seeney S, Bell S, et al. Effect of long term treatment with azithromycin on disease parameters in cystic fibrosis: a randomised trial. Thorax 2002;57:212-6.

5 Tsang KW, Ho Pl, Chan KN, et al. A pilot study of low-dose erythromycin in bronchiectasis. Eur Respir J 1999;13:361-4.

6 Currie DC, Garbett ND, Chan KL, et al. Doubleblind randomized study of prolonged higher-dose oral amoxycillin in purulent bronchiectasis. Q J Med 1990;76:799-816.

\section{Early life antibiotics and asthma}

Cullinan et al present interesting data on the association between exposure to antibiotics in early life and the subsequent expression of atopy and asthma. In keeping with other studies, they report a positive association between antibiotic receipt over the first 5 years of life and asthma. The association was, however, largely accounted for by prescriptions issued for respiratory illnesses, and the authors conclude that reverse causation was the likely explanation for this association.

The inappropriate use of antibiotics for respiratory symptoms caused by unrecognised asthma is the main potential confounding factor in observational studies attempting to demonstrate a causal link between antibiotic receipt and atopic illnesses. It is certainly plausible that GPs may prescribe antibiotics in children with symptoms such as cough and wheeze in early life. Suggestions of a casual link are strengthened by demonstration of an association when antibiotics were used for symptoms not associated with asthma. The earlier study by Farooqui and Hopkins ${ }^{2}$ did, indeed, observe an association with non-respiratory use of antibiotics and asthma; in the study by
Cullinan et al the association between nonrespiratory indicated antibiotics and atopic asthma narrowly failed to reach statistical significance. The authors acknowledge that the study was only powered to show a doubling of the odds ratio for the association between early life antibiotic use and asthma, so an association remains possible in this cohort.

The most important limitation of the study, however, is the timing of the observed early life events in relation to secular changes in asthma prevalence and antibiotic prescribing, and hence the applicability of the results to modern day settings. This study observed events occurring 30 or more years ago in the parents of the Ashford birth cohort. As is well described, the prevalence of asthma has increased greatly over the last 30 years. ${ }^{3}$ There may also have been significant increases in antibiotic prescribing over this time. The subjects in this study received an average of 3.1 and a median of 3 antibiotic prescriptions over 5 years, while we found in a recent case-control study ${ }^{4}$ of 37 children with atopy and wheezing and 37 without either that the average and median number of antibiotic courses received during the first 5 years of life was 9.9 and 7 for wheezers and 6.3 and 5 for non-wheezers. There is also evidence of earlier prescribing of antibiotics in recent times; in our study group $89 \%$ of wheezers and $68 \%$ of non-wheezers received one or more courses of antibiotics in the first year, while in the Ashford study only 396 prescriptions were issued to 746 subjects in the first year, so a maximum of 53\% children received any antibiotics.

It seems likely from the data presented that antibiotic exposure did not play a major causal role in promoting the asthma phenotype 30 years ago when both the prevalence of asthma and antibiotic prescribing to young children were significantly less than they are now, but the question of whether it may now be a significant and potentially modifiable factor remains unanswered.

M Thomas

Cotswold Cottage, Oakridge, Stroud GL6 7NZ, UK; mikethomas@doctors.org.uk

\section{References}

1 Cullinan $\mathbf{P}$, Harris J, Mills $\mathrm{P}$, et al. Early prescription of antibiotics and the risk of allergic disease in adults: a cohort study. Thorax 2004;59:11-5

2 Farooqui IS, Hopkin JM. Early childhood infection and atopic disorder. Thorax 1998;53:927-32.

3 Holgate ST. The epidemic of allergy and asthma. Nature 1999;402:B2-4.

4 Thomas M, Murray CS, Simpson B, et al. Early life antibiotic exposure and subsequent risk of asthma: a case control study. Thorax 2003;58:iii67.

\section{Recurrence of acute respiratory failure following use of waterproofing sprays}

Between January and March 2003 six patients were admitted to hospital in the Lausanne area of Switzerland with acute respiratory failure following use of a waterproofing spray for clothes and leather. Within hours of exposure all patients developed a dry cough and rapidly progressive dyspnoea. The clinical picture included severe hypoxaemia, increased white blood cell count, raised Creactive protein, and reduced carbon monoxide 


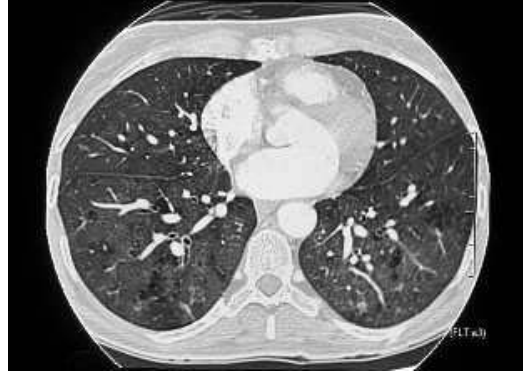

Figure 1 CT scan of thorax of a patient showing diffuse ground glass opacities.

transfer factor (TLCO). All patients had diffuse bilateral ground glass opacities on a high resolution CT scan, most often sparing the subpleural areas (fig 1). Every patient improved following treatment with oral prednisone $(0.5-0.9 \mathrm{mg} / \mathrm{kg})$ but residual dyspnoea and reduced TLCo $(<80 \%$ of predicted value) could be seen for more than 2 weeks.

Acute respiratory failure was attributed to inhalation of the waterproofing spray in view of the sudden occurrence of symptoms following exposure, the diffuse ground glass opacities without other abnormalities on the CT scan, and the absence of any other detected cause. In particular, BAL fluid was sterile for bacteria, mycobacteria, viruses and fungi. Serological tests for chlamydia and mycoplasma were performed on two patients and were negative. A nasal swab for influenza was performed on one patient and was negative.

We were, however, surprised that the patients used three different spray brands. Waterproofing sprays contain three types of components-a propellant gas (propane butane), a waterproofing agent (fluorocarbon resin), and a solvent. It appeared that the manufacturer of the fluorinated resin changed during the summer of 2002 (the same for the three brands) and that the isopropanol solvent had to be replaced with a heptane solvent. Consumers started complaining of respiratory symptoms in October 2002 and the first severe case requiring admission was reported in January 2003. The three products were withdrawn from the market at the beginning of March. During this 6 month period 153 cases of respiratory symptoms related to waterproofing sprays were reported to the Swiss Toxicological Information Centre, whereas less than 10 cases per year had been reported in the previous 7 years.

The same fluorinated resin was also distributed in Germany, the Netherlands, and the UK. In Germany the waterproofing sprays were withdrawn before they reached the consumers. During the same period five patients were admitted to hospital in the Netherlands with the same complaints. ${ }^{1}$ These sprays were also withdrawn from the Dutch market. Surprisingly, no case has yet been recorded in the UK.

However, only sprays for public use were withdrawn, not the industrial liquids. In Switzerland two additional patients developed a chemical pneumonitis with similar symptoms and diffuse bilateral ground glass opacities after using industrial waterproofing liquid with a nebuliser. Workers in the above mentioned countries should therefore be warned not to use the liquid form with nebulisers

In the past, several outbreaks of acute respiratory symptoms have been recorded in different countries including 550 in Oregon in $1992,^{23}$ in Pennsylvania and Virginia in $1993,{ }^{4}$ in Quebec in 1993, ${ }^{5}$ and in Japan between 1992 and 1993. ${ }^{6}$ Most of these epidemics followed a modification of the composition of the spray. One untreated patient developed a pulmonary fibrosis during a German outbreak in the $1980 \mathrm{~s}^{7}$ and one death was reported in Japan in the 1990s. ${ }^{8}$

Following these outbreaks, various suggestions were proposed to explain these intoxications.' In our opinion, the most likely explanation for the present outbreak is that the heptane solvent, which is more volatile than the previous one (isopropanol), allows the mist containing the new fluorinated resin to spread further in the tracheobronchial tree and to reach the alveoli where it might produce reactive metabolites inducing an alveolitis. However, the exact chemical reaction remains unknown. Because of the potentially lethal aspect of these intoxications and the possibility of new outbreaks, we consider that more research is needed on the effect of mist particle size and large analytical epidemiological studies are required to investigate this phenomenon further.

R Heinzer, J W Fitting Service de pneumologie, CHUV, Lausanne Switzerland

V Ribordy

Centre interdisciplinaire des urgences, CHUV Lausanne, Switzerland

B Kuzoe

Hôpital du Samaritain, Vevey, Switzerland

R Lazor

Service de pneumologie, HUG, Geneve, Switzerland

Correspondence to: Dr R Heinzer, c/o Beth Israel Deaconess Hospital, 330 Brookline Avenue, Stoneman 8, Boston, MA 02215, USA rheinzer@rics,bwh harvard.edu

\section{References}

1 Bonte F, Rudolphus A, Tan KY, et al. Severe respiratory symptoms following the use of waterproofing sprays. Ned Tiidschr Geneeskd 2003; 147: 1 185-8.

2 From the Centers for Disease Control and Prevention. Acute respiratory illness linked to use of aerosol leather conditioner-Oregon, 1992. JAMA 1993:269:568-9.

3 Smilkstein MJ, Burton BT, Keene W, et al. Acute respiratory illness linked to use of aerosol leather conditioner-Oregon, December 1992. MMWR Morb Mortal Wkly Rep 1993:41:965-7.

4 Burkhart KK, Britt A, Petrini G, et al. Pulmonary toxicity following exposure to an aerosolised leather protector. J Toxicol Clin Toxicol 1996:34:21-4.

5 Laliberté M, Sanfacon G, Blais R. Acute toxicity linked to use of a leather protector. Ann Emerg Med 1995;25:841-4.

6 Shintani S, Ishizawa J, Endo Y, et al. A progress report of toxicovigilance activity for acute inhalation poisonings by waterproofing spray in Japan (abstract). Clin Toxicol 1996;34:589.

7 Schicht R, Hartjen A, Still V. Alveolitis after inhalation of leather impregnation spray. Dsch Med Wochenschr 1982;107:688.

8 Ota H, Koge K, Tanaka H, et al. Acute respiratory failure due to inhalation of aerosol water proof agent (Japanese). Nihon Kokyuki Gakkai Zasshi 2000 Jun; 38:485-9.

9 Hubbs AF, Castranova V, Ma JY, et al. Acute lung injury induced by a commercial leather conditioner. Toxicol Appl Pharmacol 1997; 143:37-46.

\section{Effect of $\mathrm{PM}_{10}$ on $\mathrm{H}$ influenzae and $S$ pneumoniae}

That air pollution, and specifically particles, are harmful to health is well accepted, causing direct effects such as lung inflammation resulting in exacerbations of lung and cardiac conditions ${ }^{23}$ and being associated with admissions for pneumonia. In the 1960s Lawther et al showed that ambient particles stimulated the growth of Haemophilus influenzae in vitro, ${ }^{4}$ suggesting a direct effect of particles on bacteria themselves. However, it is not known whether this remains so for modern ambient particles where the sources are different.

To address this we have assessed the effect of $\mathrm{PM}_{10}$ (particles essentially less than $10 \mu \mathrm{m}$ in diameter) on the respiratory pathogens commonly associated with acute exacerbations of chronic obstructive pulmonary disease (COPD) and pneumonia. The effect of dilutions of extracts of $\mathrm{PM}_{10}$ on the growth of $H$ influenzae and Streptococcus pneumoniae grown in liquid broth and the effect of $\mathrm{PM}_{10}$ on microbial growth kinetics of $S$ pneumoniae was assessed.

Fresh isolates of $H$ influenzae and $S$ pneumoniae obtained from clinical specimens and the control strains $H$ influenzae NCTC 11931 and S pneumoniae ATCC 49619 were used. Particles were collected on a tapered element oscillating microbalance situated in central Birmingham, representative of an urban background site. To obtain a usable sample the surface of the filter was wetted and rinsed with two sequential aliquots of $0.5 \mathrm{ml}$ saline using a Gilson pipette until visual inspection showed no more particles coming off the filter. The two aliquots were combined and sonicated for 2 minutes to disperse the particles and aggregates. This procedure usually gives a yield of $50-300 \mu \mathrm{g} / \mathrm{ml}$ particles (Donaldson, personal communication). It is not known for certain how these concentrations relate to likely concentrations in the epithelial lining fluid, but this approach has been used in previous in vitro studies of inflammatory responses which have shown pro-inflammatory effects.

In the first experiment a 1:20 dilution of $\mathrm{PM}_{10}$ was made by adding $0.5 \mathrm{ml}$ to $9.5 \mathrm{ml}$ Iso sensitest broth (ISTA; Oxoid Ltd, Basingstoke, UK) supplemented with 5\% horse blood and $20 \mu \mathrm{g} / \mathrm{ml}$ NAD. The same volume of normal saline was added to controls. Test and control bottles were inoculated with $0.5 \mathrm{ml}$ of organism suspension at a density of 0.5 Mcfarland. A viable count was performed hourly for 5 hours while incubating at $37^{\circ} \mathrm{C}$ in $5 \% \mathrm{CO}_{2}$ using the Miles and Misra technique. ${ }^{5}$ In the growth kinetic experiment equal volumes of $\mathrm{PM}_{10}$ solution and ISTA broth (supplemented with 5\% lysed horse blood and $20 \mu \mathrm{g} / \mathrm{ml}$ NAD) were added to the first column of a sterile microtitre tray. Serial broth dilutions to a final dilution of 1:64 were performed. Control wells contained only broth and wells for sterility checks contained $\mathrm{PM}_{10}$ alone, broth alone and inoculum alone. Organism suspension, $50 \mu \mathrm{l}$ $S$ pneumoniae ATCC 49619, was added into each test and control column of the wells and incubated at $37^{\circ} \mathrm{C}$ in $5 \% \mathrm{CO}_{2}$ for 5 hours. The Miles and Misra technique ${ }^{5}$ was used to estimate the viable count of organism in each well and the differences in $\log \mathrm{cfu} / \mathrm{ml}$ between test and control were plotted against serial dilutions of $\mathrm{PM}_{10}$. This test was repeated five times using the same strain to check for reproducibility. 

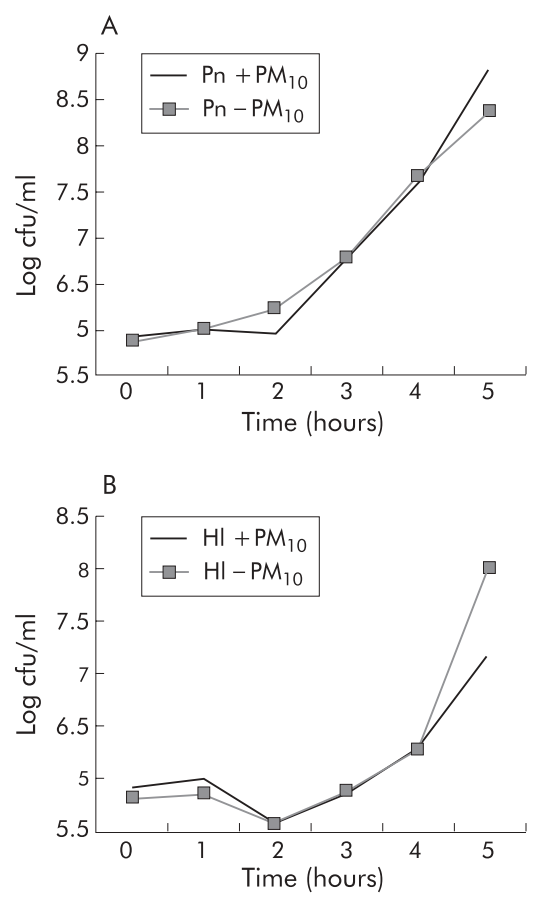

Figure 1 Growth curve against time with and without $\mathrm{PM}_{10}$ solution for (A) $S$ pneumoniae ATCC control strain and (B) $H$ influenzae NCTC control strain.

In the first experiment the number of viable cells increased progressively and in the expected pattern over time (fig lA and $\mathrm{B})$, whether in the presence or absence of $\mathrm{PM}_{10}$, for both $H$ influenzae and $S$ pneumoniae. In the growth kinetics experiment the only consistent finding was an inhibition of growth at a $\mathrm{PM}_{10}$ :broth medium dilution of 1:1 compared with the $\mathrm{PM}_{10}$ free control.

Growth of $H$ influenzae and $S$ pneumoniae is therefore neither inhibited nor promoted by incubation with $\mathrm{PM}_{10}$ at concentrations of diluted particles which are known to be able to exert pro-inflammatory effects in vitro. There was a constant inhibitory effect at a $\mathrm{PM}_{10}$ dilution of $1: 1$, possibly due to the particles themselves or to dilution of the broth by the added saline. These findings suggest that the association of air pollution with hospital admissions for exacerbations of COPD and for pneumonia is probably not mediated through direct promotion of bacterial growth. If particles alone are responsible for these effects, they are likely to be mediated by particles causing lung inflammation, thus encouraging penetration and growth of bacteria in the respiratory tract. Alternatively, gaseous pollutants may be responsible for the epidemiological findings, either directly or in conjunction with particles. This interactive mechanism is supported by the association of ambient nitrogen dioxide levels with admissions for croup, and is analogous to the potentiation of the airway response to inhaled allergen by both nitrogen dioxide $^{6}$ and ozone. ${ }^{7}$ Finally, it is possible that the particles have an effect on bacterial virulence and toxin production rather than growth. This possibility has not been tested here but warrants further study.

A Adedeii, T M A Weller

Department of Medical Microbiology, City Hospital, Birmingham B18 7QH, UK

J G Ayres

Department of Environmental and Occupational Medicine, University of Aberdeen, Aberdeen AB25 2ZP, UK; i.g.ayres@abdn.ac.uk

\section{References}

1 Pope CA, Bates DV, Reizenne ME. Health Effects of particulate air pollution: time for reassessment? Environ Health Perspect 1995;103:472-80.

2 Donaldson K, MacNee N. The mechanism of lung injury caused by $\mathrm{PM}_{10}$ In: Hester RE, Harrison RM, eds. Air pollution and health issues in environmental science and technology No 10. 1998:21-32.

3 Li XY, Gilmour PS, Donaldson K, et al. Free radical activity and pro-inflammatory effects of particulate air pollution $\left(\mathrm{PM}_{10}\right)$ in vitro and in vivo. Thorax 1996;51:1216-22.

4 Lawther PJ, Emerson TR, O'Grady FW. Haemophilus influenzae growth stimulation by atmospheric pollutants. Br J Dis Chest 1969;63:45-7.

5 Miles AA, Misra SSK, Irwin JO. The estimation of the bactericidal power of the blood. J Hygiene 1938; 38:732-49.

6 Tunnicliffe WS, Burge PS, Ayres JG. Effect of domestic concentrations of nitrogen dioxide on airway responses to inhaled allergen in asthmatic patients. Lancet 1994;344:1733-6.

7 Jorres R, Nowak D, Magnussen H. The effect of ozone exposure on allergen responsiveness in subjects with asthma or rhinitis. Am J Respir Crit Care Med 1996;153:56-64.

\section{CORRECTIONS}

doi: 10.1136/thx.2004.020307corrl

\section{PAPER BY HORVATH ET AL}

\section{(THORAX 2003;58:68-72)}

In the paper entitled "Comparison of exhaled and nasal nitric oxide and exhaled carbon monoxide levels in bronchiectatic patients with and without primary ciliary dyskinesia" by I Horvath, S Loukides, T Wodehouse, et al published in the January 2003 issue of Thorax (2003;58:68-72), there was an error in the labelling of fig 1 . The correct version of the figure is printed here. The publishers apologise for this error.
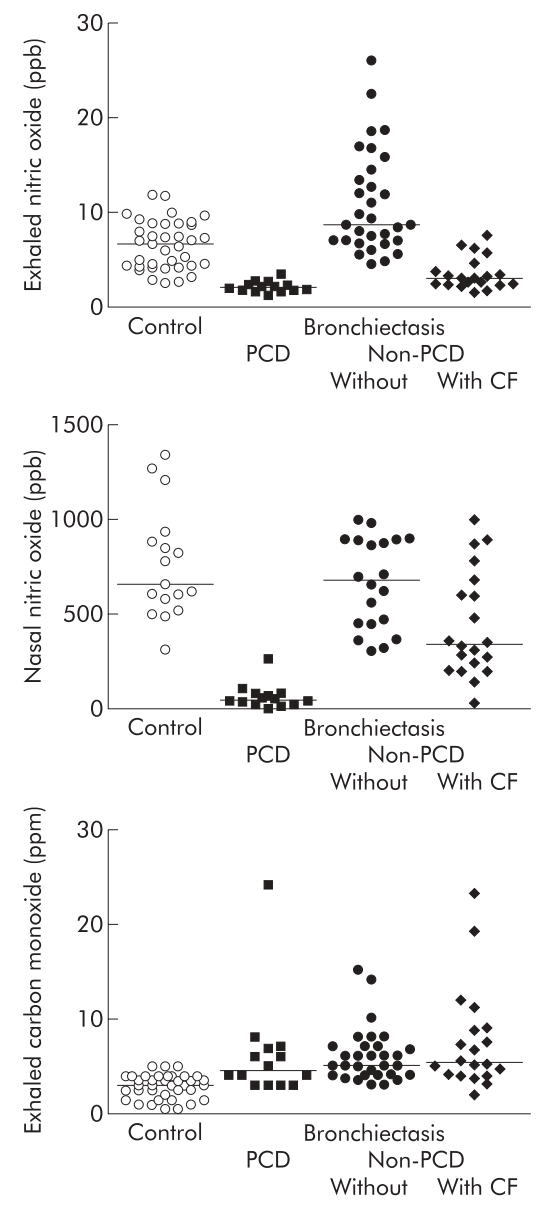

Figure 1 Exhaled $\mathrm{NO}$, nasal $\mathrm{NO}$ and exhaled $\mathrm{CO}$ concentrations in normal subjects, patients with primary cell dyskinesia (PCD) with documented bronchiectasis, and patients with non-PCD bronchiectasis with and without CF. The Kruskal-Wallis test showed siginificant differences between mediator levels $(p<0.0001)$.

doi: 10.1136/thx.2003.008912corr l

\section{PAPER BY BALDI ET AL (THORAX} 2004;59:428-32)

In the paper entitled "Prognostic significance of cyclooxygenase-2 (COX-2) and expression of cell cycle inhibitors p21 and p27 in human pleural malignant mesothelioma" by A Baldi, D Santini, F Vasaturo, et al published in the May 2004 issue of Thorax (2004;59:428-32) there was an error in the sentence beginning on line 14 of the left hand column on page 430. The sentence should have read "The median survival in patients with low p21 or p27 expression was shorter than in those with high p21 or p27 expression." The publishers apologise for this error. 